\title{
5. Barriers to implementing sustainability experienced by middle managers in the fast-moving consumer goods and retail sector ${ }^{1}$
}

\author{
Andrew Mountfield, Kelly Hrajnoha, Leslie Koh, Lija \\ Lascenko, Renata Puchala and Cornelia Schalch
}

\section{INTRODUCTION}

This empirical study explores the nature of the barriers to implementing sustainability experienced by middle managers in the Fast-Moving Consumer Goods and Retail (FMCG\&R) sector, as related to leadership practices and strategic management processes, and how these relate to the agency of these middle managers concerning sustainability within their own organisations. The organisations concerned have in majority adopted comprehensive Environmental/Social/ Governance (ESG) definitions of sustainability.

Bonn and Fisher (2011, p. 5) argue: "For organizations to achieve sustainability, managers must address the different aspects of sustainability during the strategic decision-making process and incorporate them into their corporate, business and functional level strategies." Middle managers (MMs) play a key role in an organisation's strategy execution in general (Kaplan \& Norton, 2006), and their role in successfully implementing sustainability has been noted (Haugh \& Talwar, 2016). Concerns have been expressed that implementation slows as it reaches middle management level (Kiron et al., 2017). Glavas (2012) notes that most analysis of sustainability implementation has been at the macro-level and that few studies have been made of its implementation within organisations at operational levels, and of the impact that either planned, command-and-control or emergent, agentic processes have had on behaviour or performance. As such, researching MMs' experience of barriers to implementing sustainability in their organisations represents an urgent area for exploration, and a potential source of solutions for best practices in sustainability implementation.

Given the paucity of existing empirical research, an initial study which conducted interviews with $18 \mathrm{MMs}$ from 14 companies in the FMCG\&R sector was chosen, an area of industry particularly affected by the need for speed of delivery, and increasingly focussed on sustainability implementation in response to changing consumer demands and heightened scrutiny of supply chains (Streeter, 2016). The MMs selected work for large companies with public sustainability commitments, with visible external expressions of this commitment. This chapter asks the question, to what degree MMs experience barriers to this public commitment to sustainability when charged with, as Epstein and Buhovac (2010, p. 306) describe it, "the integration of [sustainability] into the day-to-day decision making”. 


\section{LITERATURE REVIEW}

To understand the nature of the barriers to implementing sustainability experienced by MMs, the following literature review begins by looking at the role of middle managers in implementing strategy, both from a general and a sustainability-specific perspective. Two schools were analysed, each with a particular lens set: first, an organisational and leadership (O\&L) view, focussed on the organisational dimensions of company purpose, culture, engagement and agency, and stakeholder involvement, and, second, a strategic management (SM) view, which emphasises the integration of sustainability and business strategy, corresponding management systems and tools for developing targets, and links to recognition and rewards practices. This analysis was targeted towards the identification of barriers to sustainability implementation as these relate to MMs.

\section{The Role of Middle Managers in Strategy Implementation}

Traditionally (Ansoff, 1965; Hart, 1992; Lewin, 1947), MMs have not been considered part of the management process, except as providers of information and context and facilitating implementation. Certain scholars, however, have suggested that MMs attempt to influence strategy and often act as the source of new initiatives (Burgelman, 1996; Tarakci et al., 2018). Barringer and Bluedorn (1999) make the case that MMs, being closer to the market, have better stakeholder insights and have motivation to develop agentic behaviour. Tabrizi (2014) argues that, as trusted individuals, MMs may receive or adopt roles as "North Stars", taking on responsibilities for the creation and implementation of specific initiatives. Floyd and Wooldridge (1992) make the case that MMs are essential in championing alternative paths and synthesising external information that speaks to required change.

Where sustainability scholars have addressed the role of MMs, Neugebauer (2014) asserts, they tend to focus on the importance of a traditional, top-down, rational and planned approach. This, she argues, is at odds with more recent scholarship that recognises a more emergent approach to strategy formulation and implementation.

\section{An Organisation and Leadership Perspective}

The following section analyses the literature providing an O\&L perspective, identifying three key organisational dimensions important for implementing sustainability, absence or paucity of which could present a potential barrier for MMs.

\section{Purpose and communication}

Sennels (2014) argues that a corporate purpose is an "effective tool in trying to communicate strategic decisions and corporate goals in a manner understandable to employees" (p. 42). Stoughton and Ludema (2012), in their case study of three leading companies in sustainability, assert that to deploy sustainability, top leadership "aligned sustainability with their company's business purpose, created sustainability priorities, and communicated sustainability commitment both internally and externally" (p. 507). Brunton et al. (2017) argue that the internal CSR communication strategy is important for "explaining and reinforcing a company's mission and morality" (p. 33). However, a company needs to also communicate its commitment externally (Brunton et al., 2017). Without such an external pronouncement, Epstein and Buhovac (2010) 
argue that any further communication on sustainability will not be understood internally. While several scholars (e.g. Stoughton \& Ludema, 2012; Weerts et al., 2018) argue that the definition of purpose lies in the hands of senior leadership, and is, therefore, outside the purview of MMs, Petrini and Pozzebon (2010) assert that a senior-level commitment alone is only a starting point for implementation.

\section{Company culture and employee engagement}

Epstein and Buhovac (2010) argue that "a common overall organizational culture that builds on sustainability can further help managers and other decision-makers deal with the trade-offs that the simultaneous management of social, environmental, and financial goals often causes" (p. 313). Equally, changes brought forth by new strategy, Vele (2013) argues, must be "compatible with the existing organizational culture" (p. 1691).

Stoughton and Ludema (2012) argue that "differentiated viewpoints of sustainability arise within different functional areas" (p. 214). Marcus and Van de Ven (2015, p. 300) contend that sustainability implementation typically consists of multiple projects with "different levels of consensus and ambiguity". MMs, with the insights they have into their organisations (Bower, 1970) and their position as trusted leaders (Tabrizi, 2014), therefore, have a critical part to play in interpreting values within the company culture. Veland et al. (2018) assert that sustainability requires "new narratives" to change the organisational culture, and middle managers are in a unique position to act as agents or, as Valentino and Frances (2004) argue, to override corporate objectives as guardians of "corporate narratives".

To allow for implementation of sustainability into day-to-day decision-making, Epstein and Buhovac (2010) suggest that companies "build an organizational culture that motivates sustainable decision-making and behavior" (p. 313). Spillane (2005) argues for "distributed leadership practices" that allow for decentralised adaptation to a changing environment (pp. 143-144), while Crews (2010) asserts that "development of an organizational learning culture is necessary to foster a culture of sustainability" (p. 18). Nijhof et al. (2012, pp. 109-128) further argue that leaders can encourage social intrapreneurs, defined as "people within a corporation who take direct initiative" (p. 124).

\section{Stakeholder involvement}

Organisations argue for an integrated approach to sustainability in business (e.g. International Integrated Reporting Council). Yet, the role of MMs in stakeholder involvement remains ambiguous. Reporting Initiative encourages companies to consult a range of stakeholders. Crews (2010) argues that "stakeholder engagement" is one of the main leadership challenges for sustainability implementation. Posch and Speckbacher (2017) assert that: "the techniques for managing the multi-dimensionality of stakeholder value creation are underdeveloped and many firms struggle with how to implement broader stakeholder-oriented strategies" (p. 3), where MMs are directly involved with suppliers, customers and local communities. In practice, as Epstein and Buhovac (2010) argue, "corporate and societal priorities often change, as do the costs of implementing sustainability" (p. 307), leading to limitations on the effectiveness of centralised sustainability strategies. Posch and Speckbacher (2017) assert: "Middle managers have been accorded an important role as 'linking pins' that link top management to the organization making sense of its strategic visions for lower level managers and translating them into daily practice as well as embedding stakeholder expectations within the strategy" (p. 23). 


\section{A Strategic Management Perspective}

\section{Integration of sustainability and business strategy}

An important organisational dimension for sustainability implementation within the perspective of SM is the integration of sustainability into formal business strategy. As Johnson et al. (2011, p. 3) argue, SM is the "definition of a long-term direction", and for companies wanting to create and implement sustainable strategies with global and societal impact, making sustainability an integral and long-term part of doing business (Neugebauer, 2014, p. 2) - beyond statements of intent - is crucial. In this context, Henderson et al. $(2015$, p. 10) argue that for strategic sustainable change to be possible, leaders must first "articulate and shape goals" in a form communicable to the organisation. Strategies form the frames of reference for sustainability strategy and implementation and are the "cognitive maps and thinking frameworks" (Porac \& Thomas, 2006, p. 169) that operationalise broader strategic intent, and make them accessible to MMs. Formalised management processes (Kaplan \& Norton, 1996) are in this sense frames of reference designed to influence decision-making and behaviour, thus legitimising the incorporation, for example, of environmental issues (Sharma \& Sanjay Sharma, 2011). Although different strategy approaches exist (Mintzberg, 1978), authors on sustainable strategy often assume a formalised, planned, directed model (Neugebauer, 2014, p. 31). Although the value of this approach is debated (By, 2005; Herbert, 1999), a strong tradition of academic research (Ansoff, 1965; Hart, 1992; Kaplan \& Norton, 1996, 2006; Lewin, 1947) permeates sustainability research (e.g. Eccles \& Krzus, 2010) and sustainability practitioner literature (Blowfield, 2013; Rezaee, 2015), which assumes the dominance, indeed necessity, of planned strategy processes, and "disappears" the agentic and emergent.

\section{Consistent management processes and cascade of objectives to middle management}

Planned strategy proponents stress the requirement of ensuring the strategy is monitored, measured over time, and that mitigation actions are taken in case of deviation from targets (Cokins, 2004; Kaplan \& Norton, 1996). Additionally, they argue that strategic objectives must be broken down to the level of individual units and that these objectives and performance indicators will need to be aligned between units (Niven, 2003; Wirnsperger et al., 2015). Sustainability practitioners (Blowfield, 2013; Farver, 2013; Izzo and Vanderwielen, 2018; Rezaee, 2015) also argue for the integration or adoption of formal management systems. External sustainability reporting authors such as Bertinetti and Gardenal (2016) make the case for the alignment of external information with internal objectives, including and aligning risk management parameters, thus creating a consistent set of comprehensive, cascaded and aligned objectives and performance indicators.

Sustainability scholars (Judge \& Douglas, 1998; Soriano et al., 2010) have long argued for formal strategic and operational processes for sustainability implementation. Manninen and Huiskonen (2019) make the case that neglect of formal sustainability planning damages the operationalisation process by MMs. Mountfield et al. (2019) argue that, if the organisation already applies a robust management process for objective-setting, then excluding sustainability risks communicating that it is of secondary importance. Bhattacharya (2018) goes further, arguing that senior management must build a managed process that provides opportunities for MMs to expand on and take ownership of their goals. 


\section{Linking rewards to sustainability implementation}

Setting measurable objectives and cascading these to the responsible levels of the organisation also implies aligning reward processes with sustainability implementation (Farver, 2013). Noe et al. (2008) argue that any organisation that attempts to derive competitive advantage through its employees must develop a means by which managers ensure that employees' activities and outputs are congruent with the organisation's goals, though Beer and Cannon (2004) warn of the risk that employees focus purely on rewards rather than broader benefits for the organisation. While board-level compensation for the achievement of sustainability targets has received some attention (e.g. Burchman \& Sullivan, 2017), there is little visibility concerning lower management levels. Practitioner authors tend to either assume that sustainable objectives are part of an existing objective-setting and reward system (e.g. Farver, 2013) or argue that intrinsic motivation will motivate managers to implement sustainability objectives (e.g. Blowfield, 2013).

\section{RESEARCH DESIGN AND METHODS}

The objective of this research is to examine the nature of the barriers to implementing sustainability experienced by MMs in the FMCG\&R sector. This chapter follows an abductive approach (Hlady-Rispal \& Jouison-Laffitte, 2014), integrating both deductive and inductive aspects of analysis. The deductive aspect involved reviewing research concerning sustainability implementation, as seen within two schools of literature: organisation and leadership and strategic management, which were then used as a foundation for data collection. Analysis of data was performed inductively, allowing themes to emerge from the data in order to inform the theory.

\section{Data Sources}

The data collection was executed through face-to-face interviews with $18 \mathrm{MMs}$ from 14 international FMCG\&R companies in 10 countries spanning Asia, North and South America and Europe (Table 5.1).

\section{Table $5.1 \quad$ Location of interviewees}

\begin{tabular}{llll}
\hline Region & Headquarters & Regional office & Total \\
\hline Asia & 0 & 2 & 2 \\
Europe & 6 & 4 & 10 \\
Americas & 3 & 3 & 6 \\
Total & & & $\mathbf{1 8}$ \\
\hline
\end{tabular}

Given the diverse business background and geographical spread of the research team, a combination of purposive and convenience sampling (Morse, 2007) was used to recruit interviewees from the researchers' study and business networks. The following sampling criteria were used to identify potential interviewees who were able to address the various components of the research question. 


\section{Company Criteria}

\section{FMCG\&R sector}

Sampling concentrated on companies specialising in food, cosmetics, fast furniture and apparel. This sector was chosen because it is particularly affected by the need for speed of delivery, and increasingly focussed on sustainability implementation, in response to changing consumer demands, and heightened scrutiny of supply chains (Streeter, 2016).

\section{Size and geographical scope}

Companies were limited to large international organisations, with 1000 employees or more.

\section{Public commitment to sustainability}

This was crucial to ensure the relevance of the organisation for a sustainability implementation questionnaire. Minimal requirements were:

- publicly available sustainability strategy or commitment supported by the members of the Board;

- compliance with international sustainability reporting standards such as GRI or IIRC (International Integrated Reporting Council); and/or

- national and/or international sustainability certifications, memberships, awards or rankings (e.g. Dow Jones Sustainability Index, Corporate Knights, B-Corp etc.).

\section{Interview Criteria}

Participants in the study were selected who had no direct responsibility for strategy formulation, received top-down targets from their superiors, but who had line responsibilities for revenues and/or costs, with own staff and a role in an organisation's strategy execution (Kaplan $\&$ Norton, 2006). Functional responsibilities were restricted to marketing and sales (around four out of five of the sample) and supply chain management (around one out of five of the sample). Interviewees were chosen both from those working at headquarters and those based in local markets.

\section{Sampling Limitations}

Drawing on such a small sample from a wide range of contexts presents some generalisability limitations (Bell et al., 2019). While the sampling criteria reduced some of the variables such as industry, company size and public commitment to sustainability, other variables still may have reduced data comparability such as interviewees' age, gender, personality, or the sub-culture within their function or geography. Even though all interviewees reported being aware of their companies' sustainability strategy, knowledge and levels of their sustainability affinity could vary.

Acknowledging the above limitations dictated by the time and resource constraints of a group project, it is noteworthy that a similar sampling approach was already used in a study of similar nature (Salih \& Doll, 2013). Other studies on MMs and sustainability strategy implementation have tended towards deeper examinations within a single organisation (Neugebauer, 2014; Silvio \& Munck, 2015), or a high-level survey of several respondents across a wide range 
of company contexts (Posch \& Speckbacher, 2017). This study thus seeks to access a deeper understanding of the nature of barriers experienced by MMs, while not restricting research to a single company or geography. In providing a more nuanced understanding of the barriers, particularly relating to experience of leadership practices and objective-setting and monitoring systems, this study creates a foundation for further research, for example through an extensive survey to test the findings across multiple organisations.

\section{Data Collection}

The semi-structured interview format was employed to set direction for data collection with "guide questions" (Nolas, 2011, p. 23), while allowing interviewees to shape the narrative through their own stories. The interview schedule underwent a double-loop refinement process (Fig.2).

First, the literature-derived organisational dimensions that could present potential barriers were used to devise questions, based on perspectives identified within O\&L and SM literature. Reflecting the two schools within the literature, the guiding questions were divided into those relating to $\mathrm{O} \& \mathrm{~L}$, and those relating to SM, allowing for further probing based on responses, and encouraging more exploratory narrative responses by interviewees.

\section{Data Analysis}

The purpose of the data analysis was derived from the main research question and addresses the following aims and associated sub-questions:

- to identify shared and divergent themes regarding MMs' perspectives on the organisational dimensions identified in the two schools of literature;

- to explore how the dimensions relate to each other to identify the types or "classes" of barriers experienced; and

- to reflect back on the two schools of literature, and whether this distinction stands or a more nuanced/integrated view is needed.

The six analytical steps were undertaken separately by members of a research sub-group, and then compared, combined and refined to strengthen rigour. The above-described research process is described in Figure 5.1.

\section{General Limitations}

While this chapter already discussed the potential weaknesses of the research design, it is important to acknowledge other limitations relating to qualitative interviewing. Interview data may have been influenced by potential power dynamics, recording of data, and subsequent analysis and interpretation is likely to be influenced by the investigators' different professional and academic background and experiences. These subjectivity constraints were reduced by having separate, multi-member teams undertake data collection and analysis.

It is, therefore, important to stress that this study does not aim to objectively represent the population of all MMs in the FMCG\&R sector. Instead, this research offers the perspective of personal experiences from individuals within a range of companies, seeking to provide a more nuanced picture of potential barriers, which might then provide a foundation for future large-scale interrogation with a larger sample size. 


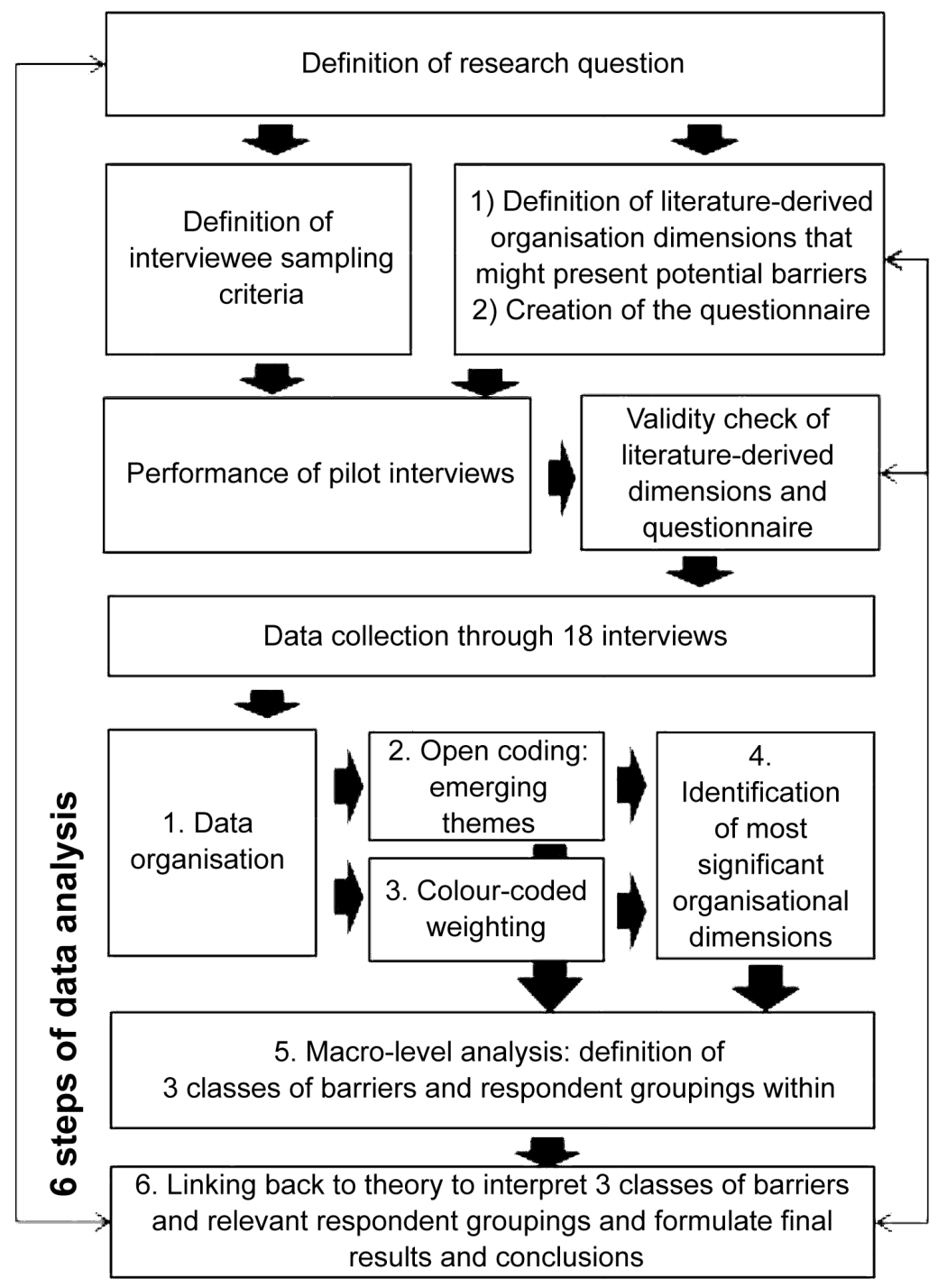

Figure $5.1 \quad$ Research process

\section{RESULTS AND DISCUSSION}

The purpose of this enquiry is to enhance understanding of the nature of the barriers experienced by MMs in the FMCG\&R sectors. Analysis of the results of the interviews led to the formulation of three classes of barriers experienced by interviewees:

- Perceptions of top-level leadership regarding sustainability topics: This class of barrier assessed the degree to which sustainability leadership of top management was perceived as absent, ambiguous or consistent. 
- Perceptions of strategic direction, key performance indicators and rewards related to sustainability, and in the context of overall corporate strategic and performance management processes: A classification was made of interviewees according to those who reported no formal sustainability objectives, key performance indicators (KPIs) or rewards, those where these were incomplete or inconsistent.

- A third group who reported willingness to take individual action and reported sense of agency: This class of barrier addressed the willingness to take independent initiatives concerning sustainability in the interviewee's own sphere of responsibility and influence.

Table 5.2 summarises the barriers to sustainability implementation experienced and the allocation of interviewees to groups, based on the analysis of the data collected.

\section{Table 5.2 Classes of barriers to sustainability implementation}

\begin{tabular}{|c|c|c|c|}
\hline Barrier class & First group & Second group & Third group \\
\hline Perceptions of leadership & $\begin{array}{l}\text { Leadership absent (interviews } \\
1,15)\end{array}$ & $\begin{array}{l}\text { Leadership ambiguous } \\
\text { (interviews } 2,3,4,5,6,7,9 \text {, } \\
10,11,12,16,17,18 \text { ) }\end{array}$ & $\begin{array}{l}\text { Leadership consistent } \\
\text { (interviews } 8,13,14 \text { ) }\end{array}$ \\
\hline $\begin{array}{l}\text { Perception of direction, } \\
\text { objectives, KPIs and rewards }\end{array}$ & $\begin{array}{l}\text { No formal objectives, KPIs or } \\
\text { rewards (interviews } 1,2,4,5,6 \text {, } \\
11,12,15,16,17 \text { ) }\end{array}$ & $\begin{array}{l}\text { Objectives, KPIs and rewards } \\
\text { incomplete or inconsistent } \\
\text { (interviews } 3,7,9,10,18 \text { ) }\end{array}$ & $\begin{array}{l}\text { Formal distributed } \\
\text { approach with delegation of } \\
\text { responsibility, objectives, } \\
\text { KPIs or rewards (interviews } 8 \text {, } \\
13,14 \text { ) }\end{array}$ \\
\hline $\begin{array}{l}\text { Sense of agency and } \\
\text { willingness to take initiative }\end{array}$ & $\begin{array}{l}\text { No or very low levels of } \\
\text { initiative-taking (interviews } \\
1,2,3,4,5,6,9,11,12,15 \text {, } \\
16,18 \text { ) }\end{array}$ & $\begin{array}{l}\text { Selective degree of } \\
\text { initiative-taking or initiative } \\
\text { adaptation (interviews } 7,8 \text {, } \\
10,17 \text { ) }\end{array}$ & $\begin{array}{l}\text { High level of initiative-taking } \\
\text { (interviews } 13,14 \text { ) }\end{array}$ \\
\hline
\end{tabular}

\section{Barrier Class: Perceptions of Leadership}

As noted above, participants' perceptions of leadership fell into three categories: participants who perceived that leadership of sustainability implementation was absent; those who believed that it was ambiguous; and those who considered leadership consistent.

\section{Leadership is absent}

The two respondents that reached this conclusion did so based on the perceived lack of any direct communication on sustainability, e.g. "Top management never talk about sustainability" and "passion for sustainability is low" (Interview 1). Leadership was therefore "practically invisible" and guidance setting priorities "zero" (Interview 15). The consequence of this for Interviewee 1 was a feeling that action on her part was of little value, while Interviewee 15 had received clear signals that economic performance was the priority. Both interview partners were aware of the external communication of the espoused importance of sustainability for their employer but reported that this had no impact on leadership at the senior levels of the organisation. Their interpretation was that their own leadership behaviour should reflect the internally espoused communication, rather than external message to stakeholders. 


\section{Leadership is ambiguous}

The key difference between this group and those interviewees who reported absent leadership lies in its ambiguity. A key theme articulated by five respondents was a perceived ambiguity between the articulation of internally focussed strategic leadership communication and a lack of substantial commitment towards operationalising sustainability, e.g. "It is very strategic, it is very talked about among the company's leadership, but it does not go down" (Interview 13). The great majority of this group of participants reported working in organisations with visible, even visionary, sustainability leadership at senior levels and strong command-and-control cultures which celebrated economic success. They articulated concerns about "mixed messages between top management talk and real life operations" (Interview 4) and a lack of guidance concerning concrete expectations, "I have to work out what this means for my region, but all the initiatives are vague and in HQ" (Interview 7). Interestingly this was not interpreted by interviewees as providing an opportunity for MM leadership, but rather a lack of genuine leadership commitment to sustainability goals. If no concrete benefits could be identified for the MM areas of responsibility then the reaction was negative: "(I understand that) sustainability is not a key differentiation pillar to my brand so it is not prioritized" (Interview 3).

\section{Leadership is consistent}

A small number of interviewees reported that sustainability leadership was consistent with the context of the entire company. Two interviewees described their experience as unproblematic and sustainability as a key factor of company success $(13,14)$. For example, the business model and leadership model were seen as aligned: "(sustainability is) part of our business model [...] and the way we work together as a team" (Interview 13), or "[sustainability] is always part of the conversation in every meeting" (Interview 13). Sustainability was seen as having been embedded in the culture, e.g. "communication from top management is clear, [but] it is sometimes so obvious for us, we have already integrated it" (Interview 14). Additionally, the manner in which sustainability was embedded was consistent with the leadership model, where a history of distributed leadership already existed and responsibility had been delegated to those closest to the markets, e.g. "[when] we purchase material at higher cost, we're taking the responsibility based on clear priorities" (Interview 14). Interviewees 13 and 14 reported that the consistency of sustainability leadership was related to a long experience of shared values in their companies, providing clear strategic guidance and high levels of leadership freedom and responsibility.

\section{Comparison of findings with literature}

The reported experience of this last group (Interviewees 13 and 14) may be seen as an echo of Henderson et al.'s (2015) argument that the fundamental requirements for sustainable change are that leaders must first "articulate and shape goals and purpose", thinking that Stoughton and Ludema (2012) articulate as the need that this occurs "in a manner that is understandable to employees". Groups 1 and 2 reported barriers to sustainability, often in organisations with strong command-and-control cultures, where top management commitment is not translated into specific objectives and priorities - and where the leadership model recognises and rewards performing according to plan. This lends support for Tarakci and colleagues' (2018) contention that visionary leadership without appropriate direction may actually reduce MM commitment, a phenomenon noted by the second group. Lastly, the argument of Marcus and Van de Ven (2015, p. 300) that the nature of a transition to sustainability requires addressing 
"degrees of values consensus and task clarity that change over time", is confirmed forcefully by Group 2.

The analysis also echoes Spillane's (2005) description of "distributed leadership practices", observed in Group 3, where leadership had set out both the importance of sustainability and the new role of MMs. Group 2's experience may be interpreted as reflecting previous experience of organisational power, leading MMs to expect that sustainability implementation conflicts must be resolved by senior management.

\section{Barrier Class: Top-down Direction, Cascaded Objectives, KPIs and Rewards}

Participants' perceptions of the impact of formal management system instruments were allocated to one of three groups, based on their reported assessment as a barrier of top-down targets, cascaded objectives and KPIs, and the linkage of these to the rewards systems, as set out in Table 5.2.

\section{Missing objectives within the formal management system}

The first group is characterised by no interviewee reporting being aware of formal sustainability objectives linked to a strategic sustainability goal. All participants, however, reported that they themselves received business-oriented departmental and individual objectives and performance indicators, linked in part to rewards policies. Interviewees reported a failure to be able to understand their expected contribution, e.g. "I don't know my part [in sustainability implementation] and I'm not challenged or asked to think about it" (Interview 16) and "I have no goals [and] the impression that sustainability is not seen as important for my area" (Interview 15). Interviewees in this group interpreted missing sustainability objectives and performance measures for their personal areas of responsibility as signifying that they were not expected to make a formal contribution to any corporate sustainability initiative or to take that initiative for their areas themselves.

\section{Inconsistent or incomplete objectives}

The second group reported the group-wide sustainability objectives or initiatives but perceived them as a barrier due to their incompleteness, e.g. "I'm aware of objectives, but I think it lacks complete cascading to us" (Interview 18). Other interviewees drew attention to the conflict they perceived behind having both sustainable and non-sustainable brands in the same company, e.g. "my brand isn't one of the sustainable ones" and "in my case, since the brand-link with sustainability is around self-esteem [social impact], no one talks about production or supply chain aspects that I'm in charge of", or to the lack of transparency of how objectives were actually set and how to contribute, e.g. "[it's] a black box" (Interview 9). Co-existence of brands that were never conceived to have sustainability at their core with others which are "positioned as "sustainable"” (Interview 10) narrows the sustainability agenda and was viewed as a restriction on implementing consistent sustainability policies, e.g. "cascading goals by brand is sometimes very fragmented" (Interview 10). Criticism of the failure to incorporate sustainability objectives into existing rewards was made, and was interpreted as a signal that sustainability was of lesser importance, e.g. "of course I will implement sustainability if it is part of my MbO [Management by Objectives targets]" (Interview 18). 


\section{Formal distributed approach with delegation of responsibility, objectives, KPIs or rewards}

In contrast, the third group of participants contrasted high-level guidelines for integrating sustainability with a management system that emphasised strategic degrees of freedom of decentralised unit. As Interviewee 8 reported: "We are performance-driven, but we have a limited number of balanced KPIs." He argued that more important factors were clarifying the role that sustainability played through the value chain, the necessity of the projection of a sustainable brand image and providing environmentally sound products to "drive business value". The role sustainability played in customer focus, e.g. "empathy with those who buy our products" evolves into a product-focus "with environmentally sound offerings", and "a real potential source of growth within the company" (Interview 8) with the tracking of "engaged customers and employees" the only formal sustainability objectives and KPIs.

It seems noteworthy, that Groups 1 and 2 were composed largely of interviewees working for organisations with well-embedded formal management systems, where MMs expected to operate with top-down objectives, and cascaded consistently to operational levels, through a rules-based, low-freedom mechanism where MMs obeyed the rules, and rewards were distributed correspondingly. Group 3 operated with higher-level objectives, where performance was monitored at a more aggregated level and many targets were the subject of MMs' use of degrees of freedom to interpret what needed to be done, subject to clarity of priorities.

\section{Comparison of findings with literature}

The analysis confirms, as reflected in Groups 1 and 2, both Henderson et al. (2015) and practitioner literature (Farver, 2013; Izzo \& Vanderwielen, 2018), those arguments that cite the absence of top management objectives embedded in formal processes as a barrier to implementation. Five Group 2 interviewees specifically cited inconsistency between financial and sustainability expectations, confirming both Manninen and Huiskonen's (2019) and Neugebauer's (2014) contention that this damages the translation of high-level objectives into operational targets. Group 3, however, challenges these perspectives, suggesting that high-level objectives for sustainability can be sufficient, where the management process provides sufficient guidance about priorities and trade-offs and is consistent across the value chain. Beer and Cannon's (2004) argument that, while financial rewards linked to objective attainment may encourage engagement, incentives may work too well, motivating employees to focus excessively on rewards instead of working more broadly for the benefit of the organisation, is echoed by Interview 18 (Group 2). Group 3 considered that rewards not directly being related to sustainability were not a significant barrier for sustainability implementation, as the sustainability had been incorporated into a consistent overall set of guidelines on decision-making, leaving room for adaptation. This echoes Jarret and Huy's (2018) description of objective-setting (in Interviews 13 and 14) as a combination of "improvisation and rigor". The decision not to rigidly cascade all business and sustainability objectives and KPIs to middle management level in this company were not perceived as a sign of incompleteness, but a conscious decision to restrict top-down goal-setting to the level required for setting clear direction while allowing freedom for adapting to context. 


\section{Barrier Class: Sense of Agency and Willingness to Take Initiative}

The third class of barrier proposed, can be considered to be related to both the leadership class and the objective/KPI class. The analysis of interviews noted a particular emphasis on participants' perceptions of their own ability to act independently, to take initiative and to have agency. This enabled interviewees to be divided into three groups: participants who perceived that they had low or no opportunity to take initiative concerning sustainability implementation; those who felt that they had limited opportunity; and those who both perceived and demonstrated strong initiative-taking.

\section{No or low levels of initiative}

The first group of participants expressed no or low levels of initiative and commented that there was little that they could initiate personally and could cite no examples of how they had introduced elements of sustainability implementation into their own areas of responsibility. This group represented the majority of participants. Lack of agency was first associated with lack of guidance concerning leadership and roles. As Interviewee 1 stated: "If we don't know our responsibility, how can we justify putting resources into action?” (Interview 1). Second, however, the perception of leadership communication and engagement were reported to be important barriers: "Since nobody ever speaks about it or feels engaged with the sustainability agenda, then nobody does anything" (Interview 4). It seems noteworthy to contrast high levels of "personal passion" reported for sustainability (with scores of 7/10 and above for interviews in Group 1) with low levels of agency. No interviewee was able to cite an example of personal initiative.

\section{Selective initiative}

A second, more restricted group of four participants demonstrated a degree of initiative through the assumption of responsibility for high-level corporate initiatives at a local level, and adapting them to local context in order to facilitate successful implementation, e.g. "We take the theoretical concepts we get from headquarters and make them fit to the needs of our market" (Interview 7). However, this initiative-taking was related to local sensitivities, in this example prompted by the perceived lack of relevance of an "LGBT [lesbian, gay, bisexual and transgender] outreach" programme, viewed as being incompatible with local culture. A further explanation for higher levels of agency was lack of headquarters resources to support local organisations, e.g. "we're used to doing most projects ourselves". Here, lack of resources was used as an example to reinforce the dominant local corporate narrative (Interview 10) concerning roles and responsibilities in the organisation. Reported levels of "passion" for sustainability were at approximately the same level as Group 1. No local, independent examples of sustainability initiatives were cited by interviewees in Group 2.

\section{High levels of initiative-taking}

An equally restricted third group of participants, composed of two participants, described and demonstrated high levels of initiative. Rather than assuming that strategic issues were the responsibility of senior management, MM focus was shifted to "white spots", i.e. areas where only MMs could perceive the need to solve "new and urgent" business and sustainability problems. This led to examples of significant strategic initiatives which emerged from the changed 
perceptions of MMs (Interview 13), e.g. "investing [their time] heavily in collaboration with competitors to change industry standards [and ...] establish sustainable business" (Interview 14).

\section{Comparison of findings with literature}

The analysis of Groups 2 and 3 confirms Neugebauer's (2014, p. 31) conclusion that sustainability research "largely assumes that sustainability strategies are made in a planned way", a view only partially confirmed by empirical evidence. Those examples of agency identified above occurred either to deliberately adapt top-down policies to perceived local conditions, as a reaction to a failure to define policy or to fill urgent gaps in these policies. Further, analysis of results supports her proposal (Neugebauer, 2014, p. 150) that this emergent sustainability strategising occurs where issues are not viewed as "salient" by senior management, and where MMs are first to recognise their importance and act independently.

Group 2 results may provide a partial confirmation of Bhattacharya's (2018) proposition that sustainability implementation requires senior management leadership to deliberately create opportunities for MMs to take ownership of sustainability strategies within a managed process, a deficit noted by a number of Group 2 interviewees. Nevertheless, initiatives identified appear more emergent than deliberate opportunities created by senior management, and more reliant on a culture of initiative than a process of implementation, considered to be absent by Groups 1 and 2.

Finally, the size of Group 1, two-thirds of the interviews, may serve as a confirmation of the applicability of Argyris and Schön's $(1974,1978)$ espoused theory and theory-in-use to sustainability leadership. Thus MM members of the organisation's espoused theory (passion for sustainability and agency) remains intact, as observed in Groups 1 and 2, while maintaining the organisational theory-in-use (top management set direction and objectives - except for minor errors and inconsistencies). However, only in Group 3 is it possible to identify examples of double loop learning taking place, where assumptions and values (role and potential agency of MMs) are questioned, and theories-in-use are changed.

\section{CONCLUSIONS}

This study set out to explore the nature of the barriers to implementing sustainability experienced by MMs.

Where MMs report perceived deficits in leadership, referring to clarity of communicated direction and commitment, and inconsistencies between words and action of top management, their interpretations and subsequent agentic behaviour was dependent on their perception of the role of top management. Where top management was considered by MMs to be responsible in general for resolving strategic questions (command-and-control), and, more specifically, for addressing ambiguities between strategic priorities, levels of agency reported by MMs concerning sustainability implementation were low.

From the perspective of formal management systems within organisations with high levels of target-setting and low levels of planned strategic freedom, MM agency was low where sustainability objectives were excluded from performance management and reward systems. Agency was also low where sustainability objectives were not seen by MMs as compatible with broader strategic or financial objectives for which they were responsible, for example, cost reduction. Agency was reported where MMs adapted planned sustainability initiatives 
which were viewed as being culturally incompatible with local social conditions, for example involving a watering-down of objectives concerning LGBT.

Agency regarding sustainability implementation through MMs was reported as high in a small number of interviews, where leadership was perceived as providing broad, unambiguous high-level guidance concerning priorities and trade-offs, and where a history of distributed leadership existed across functions and was valid for both business and sustainability topics. MMs exercised a high level of agency, strategy was often emergent and occurred at MM levels with the organisation, while stakeholder engagement was higher than in other interviews, particularly regarding influencing suppliers, competitors and customers to adopt sustainable practices.

Future research could examine this topic in further depth, and in other industries and geographies, to better understand potential solutions for addressing the role of leadership and management systems in accelerating sustainability implementation within organisations.

\section{NOTE}

1. This is an open access work distributed under the Creative Commons Attribution-NoDerivatives 4.0 International (CC BY-ND 4.0). Users can redistribute the work for non-commercial purposes, as long as it is passed along unchanged and in whole, as detailed in the License. Edward Elgar Publishing Ltd must be clearly credited as the rights holder for publication of the original work. Any translation or adaptation of the original content requires the written authorization of Edward Elgar Publishing Ltd.

\section{REFERENCES}

Ansoff, H.L. (1965) Corporate Strategy, McGraw-Hill, New York.

Argyris, C. \& Schön, D.A. (1974) Theory in Practice: Increasing Professional Effectiveness, Jossey-Bass, San Francisco, CA.

Argyris, C. \& Schön, D.A. (1978) Organizational Learning: A Theory of Action Perspective. Addison-Wesley, Reading.

Barringer, B.R. \& Bluedorn, A.C. (1999) The relationship between corporate entrepreneurship and strategic management. Strategic Management Journal, 13, 363-380.

Beer, M. \& Cannon, M. (2004) Promise and peril in implementing pay-for-performance. Human Resource Management, 43, 3-48. DOI: 10.1002/hrm.20001.

Bell, E., Bryman, A. \& Harley, B (2019) Business Research Methods, 5th edn, Oxford University Press, Oxford.

Bertinetti, G. \& Gardenal, G. (2016) Enterprise risk management and integrated reporting: Is there a synergism? In C. Mio (ed.) Integrated Reporting, Palgrave Macmillan, London. DOI: 10.1057/978-1-137-55149-8_11.

Bhattacharya, C.B. (2018) How to make sustainability every employee's responsibility. Harvard Business Review, 23 February. Retrieved 27 May 2019 from https://hbr.org/2018/02/how-to-make -sustainability-every-employees-responsibility.

Blowfield, M. (2013) Business and Sustainability, Oxford University Press, Oxford.

Bonn, I. \& Fisher, J. (2011) Sustainability: the missing ingredient in strategy. Journal of Business Strategy, 32 (1), 5-14. Retrieved 27 May 2019 from https://doi.org/10.1108/02756661111100274.

Bower, J.L. (1970) Managing the Resource Allocation Process: A Study of Corporate Planning and Investment, Harvard Business School, Division of Research, Boston, MA. 
Brunton, M., Eweje, G. \& Taskin, N. (2017) Communicating corporate social responsibility to internal stakeholders: Walking the walk or just talking the talk? Business Strategy and the Environment, 26 (1), 31-48. DOI: 10.1002/bse.1889.

Burchman, S. \& Sullivan, B. (2017) It's time to tie executive compensation to sustainability. Harvard Business Review, August. Retrieved 27 May 2019 from https://hbr.org/2017/08/its-time-to-tie -executive-compensation-to-sustainability.

Burgelman, R.A. (1996) Intraorganizational ecology of strategy making and organizational adaptation: Theory and field research. In J. Meindel et al. (eds), Cognition Within and Between Organizations, Sage, Thousand Oaks, CA. Retrieved 2 March 2019 from https://doi.org/10.1287/orsc.2.3.239.

By, R.T. (2005) Organisational change management: A critical review. Journal of Change Management, $5(4), 369-380$.

Cokins, G. (2004) Performance Management, Wiley, New York.

Crews, D.E. (2010) Strategies for implementing sustainability. S.A.M. Advanced Management Journal, $75(2), 15-22$.

Eccles, R.G. \& Krzus, M.P. (2010) One Report, Wiley, New York.

Epstein, M.J. \& Buhovac, A.R. (2010) Solving the sustainability implementation challenge. Organizational Dynamics, 39 (4), 306-315. DOI: 10.1016/j.orgdyn.2010.07.003.

Farver, S. (2013) Mainstreaming Corporate Sustainability, Amazon Fulfillment, Warsaw, Poland.

Floyd, S.W. \& Wooldridge, B. (1992) Middle management involvement in strategy and its association with strategic type. Strategic Management Journal, 13, 152-167.

Glavas, A. (2012) Employee engagement and sustainability: A model for implementing meaningfulness at and in work. Journal of Corporate Citizenship, 212 (46), 13-29.

Hart, S. (1992) An integrative framework for strategy-making processes. The Academy of Management Review, 17 (2), 327-351. Retrieved 2 February 2019 from http://www.jstor.org/stable/258775.

Haugh, H.M. \& Talwar, A.J. (2016) Linking social entrepreneurship and social change: The mediating role of empowerment. Journal of Business Ethics, 133, 643-658.

Henderson, R., Gulati, R. \& Tushman, M. (2015) Leading Sustainable Change: An Organizational Perspective, Oxford University Press, Oxford.

Herbert, T.T. (1999) Multinational strategic planning: Matching central expectations to local realities. Long Range Planning, 38 (1), 81-87.

Hlady-Rispal, M. \& Jouison-Laffitte, E. (2014) Qualitative research methods and epistemological frameworks: A review of publication trends in entrepreneurship. Journal of Small Business Management, $52(4), 594-614$.

Izzo, J. \& Vanderwielen, J. (2018) The Purpose Revolution, Berrett-Koehler Publishers, Oakland, CA.

Jarret, M. \& Huy, Q., (2018) IKEA's success can't be attributed to one charismatic leader. Harvard Business Review, 2 February. Retrieved 27 May 2019 from https://hbr.org/2018/02/ikeas-success-cant -be-attributed-to-one-charismatic-leader.

Johnson, G., Melin, L. \& Whittington, R. (2011) Micro strategy and strategizing: Towards an activity-based view. Journal of Management Studies, 40, 3-22. DOI: 10.1111/1467-6486.t01-2-00002.

Judge, W.Q. \& Douglas, T.J. (1998), Performance implications of incorporating natural environmental issues into the strategic planning process: An empirical assessment. Journal of Management Studies, 35, 241-262. DOI: 10.1111/1467-6486.00092.

Kaplan, R. \& Norton, D. (1996) The Balanced Scorecard, Harvard Business School Press, Cambridge, MA.

Kaplan, R. \& Norton, D. (2006) How to introduce a new strategy without disrupting your organization. Harvard Business Review, March, 100-109.

Kiron, D., Unruh, G., Kruschwitz, N., Reeves, M., Rubel, H. \& Meyer Zum Felde, A. (2017) At a crossroads: Progress toward our common future in uncertain times. MIT Sloan Management Review, May. Retrieved 23 March 2019 from https://sloanreview.mit.edu/projects/corporate-sustainability-at -a-crossroads/.

Lewin, K. (1947) Frontiers in group dynamics: Concept, method and reality in social science; social equilibria and social change. Human Relations, 1 (1), 5-41. Retrieved 21 May 2019 from https://doi .org/10.1177/001872674700100103.

Manninen, K. \& Huiskonen, J. (2019) Sustainability goal setting with a value-focused thinking approach: Innovation, implementation and success. In A. Aagaard (ed.), Sustainable Business Models, Palgrave Macmillan, Cham. DOI: 10.1007/978-3-319-93275-0_4. 
Marcus, A.A. \& Van de Ven, A.H. (2015) Managing shifting goal consensus and task ambiguity in making the shift to sustainability. In R. Henderson, R. Gulati \& M. Tushman (eds), Leading Sustainable Change, Oxford University Press, Oxford, pp. 298-322.

Mintzberg, H. (1978) Patterns in strategy formation. Management Science, 24, 934-948.

Morse, J. (2007) Sampling in grounded theory. In A. Bryant \& K. Charmaz (eds.), The Sage Handbook of Grounded Theory, Sage, London, pp. 229-244.

Mountfield, A., Gardner, M., Kasemir, B. \& Lienin, S. (2019) Integrated management for capital markets and strategy: The challenges of "value" vs. "values" sustainability investment: Smart Beta and their consequences for corporate leadership. In T. Wunder (ed.), Rethinking Strategic Management, Springer, Zurich, pp. 105-128.

Neugebauer, F. (2014) The Formation of Sustainability Strategies, Kassel University Press, Kassel.

Nijhof, A., Looise, J.C., De Leede, J., De Weerd-Nederhof, P., Visscher, K. \& Faculty of Behavioural, Management Social Sciences (2012) Social Intrapreneurship: A Conceptual, Theoretical and Empirical Exploration of its Meaning and Contribution, University of Twente, the Netherlands.

Niven, P.R. (2003) Balanced Scorecard Step-by-Step, Wiley, London.

Noe, R.A., Hollenbeck, J., Gerhart, B. \& Wright, P. (2008) Fundamental of Human Resource Management, 2nd edn, McGraw-Hill, New York.

Nolas, S.M. (2011) Grounded theory approaches. In N. Frost (ed.), Qualitative Research Methods in Psychology: Combining Core Approaches, McGraw-Hill Education, New York, pp. 16-43.

Petrini, M. \& Pozzebon, M. (2010) Integrating sustainability into business practices: Learning from Brazilian firms. BAR - Brazilian Administration Review, 7 (4), 362-378. Retrieved 27 May 2019 from https://www.scielo.br/pdf/bar/v7n4/04.pdf.

Porac, J.F. \& Thomas, H. (2006) Managing cognition and strategy: Issues, trends and future directions. In A.M. Pettigrew, H. Thomas \& R. Whittington (eds), Handbook of Strategy and Management, Sage, London. Retrieved 27 May 2019 from http://dx.doi.org/10.4135/9781848608313.n8.

Posch, A. \& Speckbacher, G. (2017) The role of middle management in the implementation of sustainability strategies. Academy of Management Proceedings, 1, 15505.

Rezaee, Z. (2015) Business Sustainability: Performance, Compliance, Accountability and Integrated Reporting, Greenleaf Publishing, Sheffield, UK.

Salih, A. \& Doll, Y. (2013) A middle management perspective on strategy implementation. International Journal of Business and Management, 8 (22), 22-39.

Sennels, M. (2014) What will help engage employees in the company's changing goals? Strategic HR Review, 10 (3). DOI: 10.1108/shr.2011.37210cab.003.

Sharma, P. \& Sanjay Sharma, S. (2011) Drivers of proactive environmental strategy in family firms. Business Ethics Quarterly, 21 (2), 309-334.

Silvio, S. \& Munck, L. (2015) Middle management competencies aimed in organisational sustainability: A case study in food industry. Gestão \& Regionalidade, 31 (91), 33-49.

Soriano, R., Jesús Muñoz-Torres, M. \& Chalmeta-Rosaleñ, R. (2010) Methodology for sustainability strategic planning and management. Industrial Management \& Data Systems, 110 (2), 249-268.

Spillane, J.P. (2005) Distributed leadership. The Educational Forum, 69 (2), 143-150. DOI: $10.1080 / 00131720508984678$.

Stoughton, A.M. \& Ludema, J. (2012) The driving forces of sustainability. Journal of Organizational Change Management, 25 (4), 501-517. DOI: 10.1108/09534811211239191.

Streeter, A. (2016) Ethical Corporation, FMCG Briefing: Who's moving fastest on sustainability? Retrieved 24 July 2019 from http://www.ethicalcorp.com/fmcg-sustainability-briefing-whos-moving -fastest-sustainability.

Tabrizi, B. (2014) The key to change is middle management. Harvard Business Review, October. Retrieved 3 March 2019 from https://hbr.org/2014/10/the-key-to-change-is-middle-management.

Tarakci, M., Ateş, N.Y., Floyd, S.W., Ahn, Y. \& Wooldridge, B. (2018) Performance feedback and middle managers' divergent strategic behavior: The roles of social comparisons and organizational identification. Strategic Management Journal, 39, 1139-1162. Retrieved 26 April 2021 from https:// doi.org/10.1002/smj.2745.

Valentino, C.R. \& Frances, W.H. (2004) The role of middle managers in the transmission and integration of organizational culture. Journal of Healthcare Management, 49 (6), 393-404. 
Veland, S., Scoville-Simonds, M., Gram-Hanssen, I., Schorre, A.K., El Khoury, A., Nordbø, M.J., Lynch, A.H., Hochachka, G. \& Bjørkan, M. (2018) Narrative matters for sustainability: The transformative role of storytelling in realizing $1.5^{\circ} \mathrm{C}$ futures. Current Opinion in Environmental Sustainability, 31 , 41-47.

Vele, C.-L. (2013) Organizational culture and strategy: How does it work? An empirical research. Annals of the University of Oradea: Economic Science, 22 (1), 1690-1697. Retrieved 27 May 2019 from https://econpapers.repec.org/article/orajournl/v_3a1_3ay_3a2013_3ai_3a1_3ap_3a1690-1697.htm.

Weerts, K., Vermeulen, W. \& Witjes, S. (2018) On corporate sustainability integration research: Analysing corporate leaders' experiences and academic learnings from an organisational culture perspective. Journal of Cleaner Production, 203, 1201-1215. DOI: 10.1016/j.jclepro.2018.07.173.

Wirnsperger, F., Gackstatter, T. \& Möller, K. (2015) Performance Management: Konzept, Erfahrungen und Ausgestaltung einer neuen Disziplin. Controlling - Zeitschrift für erfolgsorientierte Unternehmenssteuerung, 1, 74-80. 